\title{
IMPACTOS SOCIOAMBIENTAIS CAUSADOS PELA TRANSNORDESTINA NO MUNICÍPIO DE BREJO SANTO-CE
}

\author{
SOCIO-ENVIRONMENTAL IMPACTS CAUSED BY TRANSNORDESTINA \\ IN THE MUNICIPALITY OF BREJO SANTO-CE
}

\begin{abstract}
Ronnielle Cabral Rolim ${ }^{1}$
Anna Christina Farias de Carvalho ${ }^{2}$

RESUMO: O presente artigo é resultado de uma análise preliminar acerca de alguns impactos socioambientais que prejudicam a qualidade de vida e a qualidade ambiental das populações residentes nos Bairros Renê Lucena I e II, Alto da Bela Vista e do Sítio Lagoa do Mato I. Estas três comunidades estão diretamente relacionadas com a implantação da Ferrovia Transnordestina e as respectivas alterações observadas no meio social e ecológico, além de obter dados a respeito dos fatores econômico, cultural, segurança pública e aspectos técnicos da obra. É apresentada uma discussão conceitual em relação ao direito a um ambiente equilibrado e saudável, delineando propostas que atenuem os impactos após o processo de Licença de Instalação e de Operação da mesma.
\end{abstract}

Palavras- chave: Ferrovia. Qualidade Ambiental. Qualidade de Vida.

ABSTRACT: The present article is resulted of a preliminary analysis concerning some partnerenvironmental impacts that they harm the life quality and the environmental quality of the resident populations in the Neighborhoods Renê Lucena I and II, Alto da Bela Vista and Sítio Lagoa do Mato I These three communities are directly related with Ferrovia Transnordestina's implantação and the respective alterations observed in the social and ecological way, besides obtaining data regarding the economic, cultural factors, public safety and technical aspects of the work. A conceptual discussion is presented in relation to the right to a balanced and healthy atmosphere, delineating proposed that attenuate the impacts after the process of License of Installation and of Operation of the same.

Keywords: Line of Iron. Environmental Quality. Quality of Life.

\section{INTRODUÇÃO}

A Transnordestina é um empreendimento que envolve recursos da ordem de $\mathrm{R} \$ 4,5$ bilhões, ela faz parte do PAC (Plano de Aceleração do Crescimento) de caráter privado onde o governo federal entra com os recursos financeiros. A mesma deve ligar o interior do Nordeste aos portos de

\footnotetext{
${ }^{\mathrm{I}}$ Licenciado em Ciências pela Universidade Regional do Cariri (URCA) e Especialista em EaD e Novas Tecnologias pela FAEL e especialista em Educação Ambiental pela Universidade Regional do Cariri - URCA. Mestrando pela FACEM e formador de Ciências na Rede Municipal de Caucaia-CE. E-mail: tio_ronni@hotmail.com.

2 Professora Adjunta do Departamento de Ciências Socais da Universidade Regional do Cariri - URCA. Doutora em Sociologia pela Universidade Federal da Paraíba - UFPB. E-mail: anna_crica@hotmail.com.
} 
Pecém (CE) e Suape (PE). Até agora, somente o trecho de 96 quilômetros entre os municípios de Salgueiro, em Pernambuco, e Missão Velha, no Ceará, está recebendo as obras de terraplanagem para a colocação de trilhos.

A Ferrovia referida é um grande empreendimento que deve beneficiar o escoamento de mercadorias do interior para o litoral. Um projeto de tamanha magnitude deve obedecer aos termos legais que rezam o Conselho Nacional do Meio Ambiente (CONAMA) sobre normas e padrões compatíveis com o meio ambiente ecologicamente equilibrado e essencial à sadia qualidade de vida, ainda que seja o transporte ferroviário seja reconhecido como o meio de transporte terrestre que, intrinsecamente, gera o menor impacto ambiental, pois uma tonelada de carga em rodovias planas de pavimentação lisa requer quatro vezes mais energia não renovável do que é exigido nas estradas de ferro (FERROVIA CENTRO-ATLÂNTICA SA, 2002).

Conforme a Resolução n ${ }^{\circ}$ oI/86 do (BRASIL, 1986), impacto ambiental pode ser definido como:

Qualquer alteração das propriedades físicas, químicas e biológicas do meio ambiente, causada por qualquer forma de matéria ou energia resultante das atividades humanas que, direta ou indiretamente, afetam a saúde, a segurança e o bem-estar da população; as atividades sociais e econômicas; a biota e a qualidade dos recursos ambientais.

Conforme o inciso II do artigo 6. da referida Resolução, o impacto ambiental pode ser positivo (trazer benefícios) ou negativo (adverso), e pode proporcionar ônus ou benefícios sociais. Não se pode falar em impacto, sem qualificá-lo, para fazer um juízo de valor, da mesma forma que não se pode falar em comportamento, sem qualificá-lo.

Tanto as rodovias quanto as ferrovias promovem impactos significativos apesar de intensidades distintas. A Transnordestina é enquadrada como uma atividade modificadora do meio ambiente, sujeita a elaboração do Estudo de Impacto Ambiental (EIA) e Relatório de Impacto Ambiental (RIMA) de acordo com o Artigo 2. ㅇ da Resolução CONAMA oı/86. Os estudos acima citados possuem um caráter generalista, enquanto este trabalho avalia in loco, principalmente às comunidades mais próximas afetadas e as alterações ínsito no meio ambiente para acomodação do projeto. O Licenciamento Ambiental fornece um estudo sobre os impactos ambientais, além do monitoramento da biota no decorrer da instalação e operação dos empreendimentos, porém não garante por si só o equilíbrio ecológico e a qualidade de vida, devido principalmente à rapidez com que são feitos esses estudos (BRASIL, 1986).

Considera-se, de maneira geral, que a qualidade de meio ambiente constitui fator determinante para o alcance de uma melhor qualidade de vida. Assim sendo, Oliveira (1983) apud Machado (1997) salienta que a qualidade ambiental está intimamente ligada à qualidade de vida, pois 
vida e meio ambiente são inseparáveis, o que não significa que o meio ambiente determina as várias formas e atividades de vida ou que a vida determina o meio ambiente. $\mathrm{Na}$ verdade, o que há é uma interação e um equilíbrio entre ambos que variam de escala em tempo e lugar.

A Natureza reage procurando sempre um novo ponto de equilíbrio dinâmico; muitas vezes este é alcançado, porém, nunca é igual ao estado anterior. Faz-se necessário a intervenção humana para minimizar os efeitos negativos das alterações promovidas e potencializar a recuperação do espaço físico envolvido.

A justificativa do presente trabalho está pautada na importância da análise dos principais impactos no âmbito social e ambiental durante a implantação das obras da Ferrovia Transnordestina no município de Brejo Santo-CE. O escopo foi quantificar os principais impactos absorvidos pelas populações locais, no meio ambiente e verificar como estes reagem a tais alterações no período de estudo, além de propor medidas amenizadoras que visem à redução das alterações já mencionadas a médio e longo prazo.

\section{Material e Métodos}

A área de estudo abrange os perímetros da Ferrovia Transnordestina nas delimitações da zona urbana e rural. A primeira alberga os Bairros do Renê Lucena I e II e Alto da Bela Vista localizados na cidade de Brejo Santo-CE (Fig. I). São bairros de alto índice de crescimento na construção civil, suas populações são compostas, na maioria, por pessoas que possuem apenas o Ensino Fundamental completo e empregadas no setor de serviços. Ainda se caracteriza como uma comunidade com elevado índice de marginalidade, pois muitas vezes serve de abrigo para delituosos oriundos de outros municípios próximos principalmente em épocas festivas.

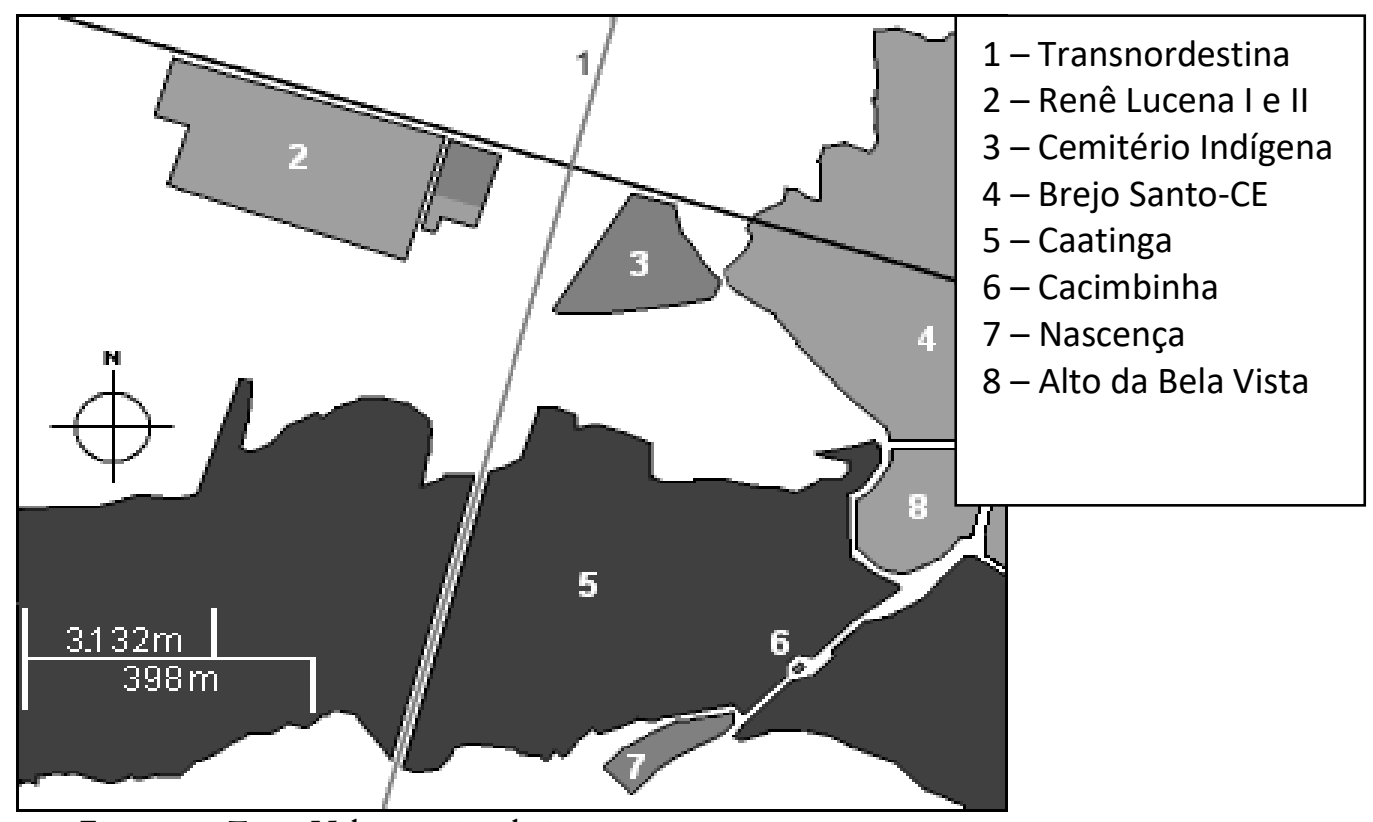

Figura I - Zona Urbana: vias, bairros e vegetação. 
Fonte: Google Earth.

Organização e Digitalização: Ronnielle Cabral, 2009.

A segunda, mais ao sul, comunidades rurais pertencentes à Lagoa do Mato I que se distanciam da cidade aproximadamente cinco quilômetros, tipicamente agropastoris e que também foi totalmente segmentada pelas obras da Transnordestina (Fig. 2).

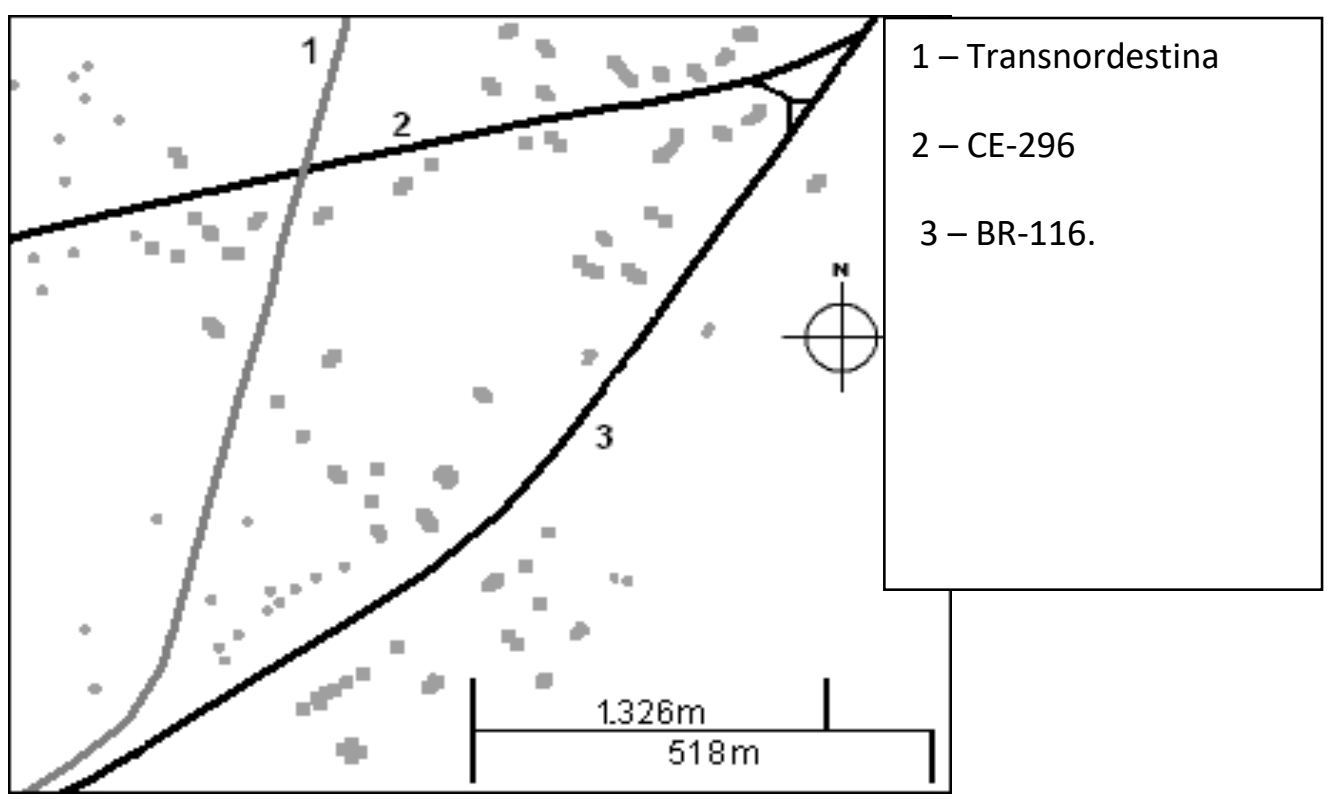

Figura 2 - Zona Rural: vias e residências, exceto vegetação.

Fonte: Google Earth.

Organização e Digitalização: Ronnielle Cabral, 2009.

Este estudo trata-se de uma pesquisa descritiva com abordagem quantitativa desenvolvida através de formulário, por ser um instrumento de coleta de dados prático e eficaz. As fontes de pesquisas formam as comunidades citadas anteriormente e colhida entre dezembro de 2008 a fevereiro de 2009 com uma amostragem de 250 declarações.

Foram realizadas visitas mensais ao segmento da vegetação local com características, predominante de Caatinga nas imediações do Bairro Renê Lucena I e II e Alto da Bela Vista entre as seguintes datas: fevereiro de 2008 a abril de 2009, para verificar as mudanças ocorridas em sua composição.

Alguns moradores do Bairro São Francisco e do Sítio São Felipe, também foram submetidos à entrevista com o objetivo de adquirir o máximo de informações referentes aos impactos sonoros da obra em seus imóveis e bens no mesmo período referido. As medições de distância e os posicionamentos geográficos foram obtidos através do programa Google Earth de propriedade do Software Google, versão 5.0.11337.1968. Todos os dados digitais coletados estão disponíveis para visualização na página: http://depositfiles.com/pt/files/4nlvıvswb. 


\section{Resultados e Discussão}

\section{Zona Urbana}

Fatores socioculturais - na direção leste há uma unidade escolar denominada E.E.F. Historiador Padre Antônio Gomes de Araújo e uma creche na comunidade designada, C.E.I. Maria Alacoque. Estas estão a menos de $190 \mathrm{~m}$ de onde vão passar os trilhos dos trens.

Já no sentido oeste existe um marco importantíssimo na formação da História Cultural do município, a Nascença. Constitui-se de um açude estimado em Io.ooom $^{3}$ e que se distancia das linhas aproximadamente $590 \mathrm{~m}$. Segundo Leite (2009), a origem de Brejo Santo está ligada às minas d'água existente na base da comunidade do Alto da Bela Vista, especialmente ao grande reservatório que tem o nome de Nascença.

Além disso, ainda há o Cemitério Indígena a menos de $270 \mathrm{~m}$ situado na propriedade do Sr. Luiz da Silva Bastos, local onde foram encontrados diversos artefatos dos Índios Cariris, primeiros habitantes que viveram nestas terras.

Nas escavações foram encontradas três camocins contendo os restos mortais e utensílios usados pelos selvagens [...] No camocim que foi encontrada a criança havia objetos de uso dela, tais como passarinhos de barro, expressão artística de nossa silvícola, e pedras coloridas que talvez servissem de brinquedo para o garoto. (CAVALCANTE, 2002, p. 78)

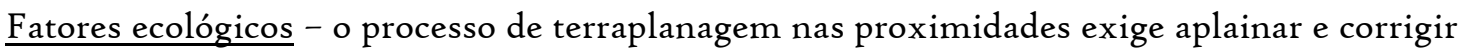
o relevo acidentado que vai de encontro com o bioma local. Este se situa no cume sobre uma formação rochosa arenítica com desnível médio de $46 \mathrm{~m}$ que protege em sua base tanto a Nascença como também uma fonte natural denominada, Cacimbinha a menos de $820 \mathrm{~m}$ que abastece inúmeras casas com água potável e gera divisas para aqueles que a comercializam.

Com a concretização do projeto cujas bordas possuem $30 \mathrm{~m}$ de largura, estas amplificam o efeito de borda permitindo ainda mais o processo da ação antrópica por parte dos moradores dos Bairros Renê Lucena I e II e Alto da Bela Vista. Alguns moradores por falta de emprego, alimento e baixos benefícios adentram na vegetação e realizam a fabricação de carvão artesanal, chamada popularmente de "carvoeiros" seguem desmatando e queimando espécies nativas para tal propósito. Em uma das excursões a vegetação, foi possível flagrar a ação de um senhor com cerca de cinquenta anos e acompanhado de uma criança com aproximadamente nove anos que o auxiliava na fabricação de carvão. $O$ frágil bioma ainda tolera a caça de aves e répteis com armas rústicas para alimentação e comércio ilegal de animais, também observado durantes a pesquisa de campo. Todas as práticas 
são desenvolvidas sem nenhum controle ou denúncia. Também foi possível colher evidências claras de uma atividade econômica extrativista, extinta hoje, desenvolvida há cerca de duas décadas entre os Bairros Renê Lucena I e II e a vegetação, a extração de blocos de paralelepípedos para a pavimentação das vias públicas locais. Foram encontrados quatro pontos de remoção, sendo um deles a $20 \mathrm{~m}$ da Cacimbinha.

A vegetação em questão encontra-se coberta por uma delgada camada de poeira que modifica sua coloração; ela funciona como absorvente de poluente, minimiza a erosão do solo e os efeitos resultantes sobre a qualidade do ar o que reduz uma diminuta porcentagem da poeira que recai sobre os domicílios próximos. Um dos representantes da fauna local tornou-se pouco aparente após o processo de Licenciamento de Instalação, o tiú (Tupinambis teguixin), antes visto com maior frequência nas expedições passadas.

A obra evolui tanto no trabalho vespertino como no período noturno com caminhões e retroescavadeiras. As máquinas a diesel também contribuem com uma parcela de emissão de partículas poluentes e sua operação perturba os animais de hábitos noturnos.

Qualidade de vida - as atividades de obra de construção resultam na emissão de particulados, prejudicam a qualidade do ar (poeiras) causadas pelas escavações, explosões, transportes de materiais e trânsito de veículos leves e pesados. A poeira gerada representa $43 \%$ das queixas registradas, ressaltam os moradores que os domicílios são varridos inúmeras vezes ao dia.

E 29\% destacam o aumento do nível de ruídos e vibrações que comprometem a qualidade do ar e aumentam a poluição sonora; este último é oriundo do maquinário e, principalmente, das explosões, as quais podem ser claramente ouvidas de localidades mais afastadas como o Bairro São Francisco, parte baixa da cidade a mais de $2 \mathrm{~km}$ de distância; e o Sítio São Felipe, parte alta do município a $8 \mathrm{~km}$ de distância e $300 \mathrm{~m}$ de altitude aproximadamente.

As explosões geram altas nuvens de poeira que caem sobre as casas adjacentes que somadas à poluição sonora causam cefaleia, problemas respiratórios e stress, principais sintomas relatados pelos moradores. Algumas explosões são tão fortes que fazem objetos como forros e portas vibrarem, devido à vasta amplitude da onda sonora produzida pelo fenômeno descrito. Geralmente são duas explosões diárias, uma ocorre antes das I2h e outra após as I6h. Tamanhas estas que algumas casas apresentam rachaduras (Fig. 3) e os moradores não sabem a quem recorrer para reparar os estragos em seus bens. 


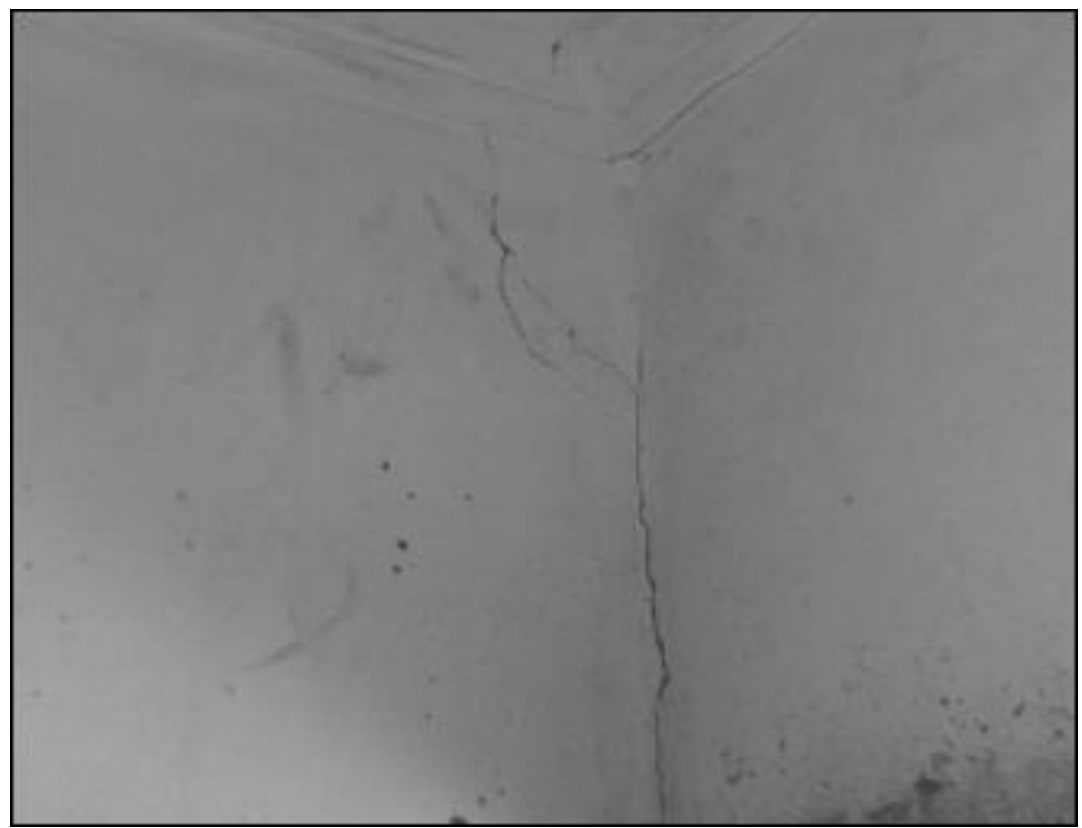

Figura 3 - Fissuras na parede e forro.

Foto: Ronnielle Cabral, 3I/o2/2009.

Por meio de conversas com moradores e visita de campo foi possível constatar algumas residências com alterações em sua estrutura oriundas do processo de terraplanagem. "As explosões são muito fortes. O chão, portas e forro tremem violentamente." (Depoimento Sra. Josefa Bernardino da Silva, 2009).

Fatores econômicos - foi possível coletar que somente 8\% dos moradores estão empregados diretamente e/ou indiretamente. Outro ponto de interesse foi que $76 \%$ dos residentes acreditam veementemente que a linha férrea vai beneficiar a comunidade de alguma forma. Os comerciantes crêem na valorização imobiliária e outros amargam prejuízos com a poeira soerguida pelas explosões e veículos em geral, como, por exemplo, os lojistas. O bairro ostenta inúmeros pontos comerciais de médio e pequeno porte: bares, mercadinhos, mercantis, pequenas lojas, cabeleireiros e serviços autônomos.

Aspectos técnicos da obra - com o objetivo de minimizar a geração de partículas emitidas, as vias de acesso ao local das obras são umedecidas através de carros-pipas, porém sua atividade foi constatada somente nos primeiros meses, cessando desde então. Também foi possível constatar a ausência de placas de sinalização indicando o tráfego de veículos e máquinas pesadas até o entorno do mês de março do decorrente ano. 
O progressivo desgaste do piso (asfalto) que liga o bairro ao centro da cidade foi acentuado com o aumento do fluxo de veículos. Estes, „, ao transitarem, formam uma cortina de poeira que comprometem a visualização e que acaba recaindo sobre a comunidade.

Praticamente, 100\% dos entrevistados, afirmam que não receberam nenhuma orientação sobre os eventos de que iriam suceder no perímetro da comunidade e não há nenhum programa de assistência aos moradores oferecidos pela empresa responsável das obras de terraplanagem.

Segurança pública - em relação ao tráfego de pedestres, apenas $4 \%$ dos moradores se mostraram preocupados em relação a acidentes de que envolvam crianças, veículos e trens; e $28 \%$ não se manifestaram. Ao lado da linha férrea a menos de $160 \mathrm{~m}$ existe um estádio de futebol que aloca diversos eventos e atrai inúmeras pessoas durante todo o ano.

\section{Zona Rural}

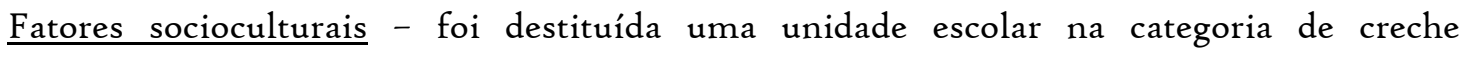
denominada, C.E.I. Raimundo Gonçalves de Sousa. Esta assistia às crianças locais, porém era mais um obstáculo que impedia a passagem da via-férrea. Segundo os moradores, esta foi indenizada num valor de oitenta mil reais e seus alunos foram dispersos para outras unidades próximas que lecionam o Ensino Fundamental.

Fatores ecológicos - para a implantação do projeto foi necessário aterrar um açude particular voltado para manutenção bovina que foi devidamente indenizado. Alguns moradores acreditam que com a terraplanagem haja o acúmulo de água em determinados pontos podendo prejudicar terrenos adjacentes que os utilizam para diversos fins.

Qualidade de vida - 48\% reclamam do índice de marginalidade que se elevou após o início das obras, justificam que o processo de terraplanagem gera abrigo propício para delinquentes se ocultarem, cometer furtos e uso de drogas. E 39\% ressaltam sobre o elevado índice de prostituição decorrente, por parte, dos trabalhadores da obra que assediam as mulheres locais, que acaba indo contra os valores e costumes da localidade em estudo.

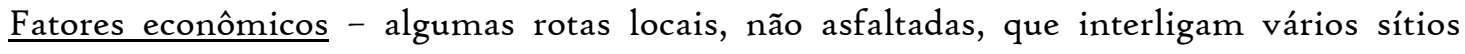
tiveram de ser alteradas e/ou prolongadas o que culminou com a inquietude de alguns moradores que recorriam a tais para o transporte de seus produtos agrícolas, mercadoria e alunos. 
Segurança pública - de modo geral, $27 \%$ dos entrevistados, relatam certa intranquilidade e insegurança, pois não há policiamento ostensivo na área e com a modificação do quadro ambiental há uma maior exposição de seus bens e integridade física.

\section{Conclusão}

Ao verificar os resultados obtidos foi possível constatar uma relativa acomodação dos moradores urbanos, pois se limitavam a conceber apenas os efeitos mais imediatos dos impactos ou aqueles que os afetavam financeiramente. A conservação do bioma e do legado histórico permanece em segundo plano. Em contrapartida, alguns moradores da área rural, ligados mais fortemente a meio ambiente, atribuíram valores e razões que demonstram uma dependência dos recursos naturais para sua sobrexistência, qualidade de vida e conservação do meio ambiente.

A princípio, os impactos positivos, resumem-se a existência de um aquecimento econômico local oriundo dos empregos gerados e, principalmente, pela imensa massa trabalhadora vinda de outros municípios e temporariamente abrigada em Brejo Santo-CE, usufruindo dos setores alimentícios, hoteleiro e serviços em geral.

Comprovou-se a hipótese de que os impactos negativos superam por muito os impactos

positivos justificados desde fatores socioculturais os aspectos técnicos da obra. E que os resultados convergem para uma demonstração intrínseca entre grau de escolaridade das comunidades citadas em relação com a conservação da qualidade ambiental e consequentemente a de qualidade de vida.

\section{Bibliografia}

BERNARDO, Christianne. et al. Curso básico de direito ambiental: comissão de direito ambiental. Rio de Janeiro: $\mathrm{OAB} / \mathrm{R}, 2002$.

BRASIL. Conselho Nacional do Meio Ambiente. Resolução n.oor, de 23 de janeiro de 1986. Dispõe sobre critérios básicos e diretrizes gerais para o Relatório de Impacto Ambiental RIMA. Diário Oficial [da] República Federativa do Brasil, Brasília, DF, i7 fev. 1986.

BURSZTYN, Maria Augusta Almeida. Gestão ambiental instrumentos e práticas. Brasília: Editora do IBAMA, 1994 .

CAVALCANTE, Francisco Mirancleide Basílio. Memórias de Brejo Santo: dados bibliográficos de homenageados em logradouro público. Fortaleza: Gráfica, 2002. v. I

FERROVIA CENTRO-ATLÂNTICA S.A. A empresa. Disponível em: <http://www.centroatlantica.com.br>. Acesso em: 3 de fevereiro de 2009. 
GUERRA, Antônio José Teixeira; CUNHA, Sandra Baptista. Impactos ambientais urbanos no Brasil. Rio de Janeiro: Bertrand Brasil, 20oI.

MACHADO, L. M. C. P. Qualidade Ambiental: indicadores quantitativos e perceptivos. In: MARTOS, H. L.; MAIA, N. B. Indicadores ambientais. Sorocaba: Bandeirante Ind. Gráfica S.A, 1997, p. 15-21.

NÓBREGA, Fernando Maia. Brejo Santo: sua história e sua gente. Fortaleza: IOCE, 198r.

LEITE, Maria Santana. A Nascença: da origem aos dias atuais. Disponível em: 〈http://recantodasletras.uol.com.br/artigos/203756〉. Acesso em: 17 de fevereiro de 2009. 